\title{
Characterization of Growth Sectors in Synthetic Quartz Grown from Cylindrical Seeds Parallel to [0001] Direction
}

\author{
Pedro Luiz Guzzo ${ }^{\text {a*, Armando Hideki Shinohara }}{ }^{\text {a }}$,Harlan Allen Dantas Costa ${ }^{\mathrm{a}}$ \\ Alberto Arnaldo Raslan ${ }^{\mathrm{b}}$, Carlos Kenichi Suzuki ${ }^{\mathrm{c}}$,Walter Mendes Azevedo ${ }^{\mathrm{d}}$ \\ ${ }^{a}$ Departamento de Engenharia Mecânica, Universidade Federal de Pernambuco \\ Avenida Acadêmico Hélio Ramos, s/n, 50740-530 CDU Recife - PE, Brazil \\ ${ }^{\mathrm{b}}$ Faculdade de Engenharia Mecânica, Universidade Federal de Uberlândia \\ Campus Santa Mônica, Bloco 1R, 38400-902 Uberlândia-MG, Brazil \\ ${ }^{\mathrm{c}}$ Faculdade de Engenharia Mecânica, Universidade Estadual de Campinas \\ Cidade Universitária Zeferino Vaz, C.P. 6122, 13083-970 Campinas - SP, Brazil \\ ${ }^{\mathrm{d}}$ Departamento de Química Fundamental, Universidade Federal de Pernambuco \\ Avenida Prof. Moraes Rêgo, s/n, 50670-901 CDU, Recife-PE, Brazil
}

Received: January 28; Revised: September 28, 2003

\begin{abstract}
In the present study, the morphology and the impurity distribution were investigated in growth sectors formed around the [0001] axis of synthetic quartz crystals. Plates containing cylindrical holes and cylindrical bars parallel to [0001] were prepared by ultrasonic machining and further used as seed-crystals. The hydrothermal growth of synthetic quartz was carried out in a commercial autoclave under $\mathrm{NaOH}$ solution during 50 days. The morphologies of crystals grown from cylindrical seeds were characterized by X-ray diffraction topography. For both types of crystals, $+\mathrm{X}-$ and $-\mathrm{X}$ - growth sectors were distinctly observed. Infrared spectroscopy and ionizing radiation were adopted to reveal the distribution of point defects related to $\mathrm{Si}-\mathrm{Al}$ substitution and $\mathrm{OH}$ species. It was found a different distribution of Al-related centers in relation to the crystals grown from conventional Y-bar and Z-plate seeds.
\end{abstract}

Keywords: synthetic quartz, impurity segregation, infrared spectroscopy, X-ray topography

\section{Introduction}

Since the beginning of the massive production of acoustic resonators in the early days of 1940's, defect structures of quartz have been extensively investigated in both natural and cultured crystals. Cultured or synthetic quartz is grown under high pressures and temperatures using hydrothermal growth ${ }^{1}$. In the process, quartz is grown on seeds placed in the autoclave above the nutrient material, which is usually natural quartz. The temperature of the nutrient zone is higher than that of the seed-crystal zone. The solution commonly used is sodium hydroxide or sodium carbonate. The seeds used to growth commercial quartz are generally Y-bar and Z-plate seeds with a long [10 10$]$ direction. For this reason, the characterization of structural defects in synthetic quartz has been constrained to sectors regions appearing around the $\mathbf{Y}$-axis, i.e., Z-, S-, $+\mathrm{X}$ and $-\mathrm{X}$ - sectors.

*e-mail:pguzzo@ufpe.br

Articles presented at the XV CBECIMAT, Natal - RN, November de 2002.
By using complementary analytical techniques, it has been shown that the concentration of $\mathrm{Al}, \mathrm{Li}, \mathrm{Na}$ and $\mathrm{OH}-$ species are not incorporated uniformly in the sector regions grown around the [10 $\overline{1} 0]$ direction ${ }^{2-6}$. Quantitative analyses carried out in several runs of synthetic quartz confirmed that $\mathrm{Al}$ and $\mathrm{Li}$ content are lower for Z-growth sectors and increase in the sequence $\mathrm{Z}<<+\mathrm{X}<-\mathrm{X}<\mathrm{S}$; while $\mathrm{Na}$ and $\mathrm{OH}$-species increase in the sequence $\mathrm{Z}=+\mathrm{X}<\mathrm{S}<<-\mathrm{X}$. Until now, only few works studied the distribution of structural defects in growth sectors formed from seed-crystals with unconventional crystallographic orientation. Ionizing irradiation performed in crystals grown from Z-cut seeds showed that substitutional $\mathrm{Al}$ is easier to be introduced on minor rhombohedral $(z)$ faces than on the basal plane $e^{7}$. Similar results was found by Armington et al. ${ }^{8}$ when they com- 
pared the content of substitutional $\mathrm{Al}$ in crystals issued from Z-cut and mayor rhombohedral $(r)$ seed-crystals, i.e., rhombohedral faces incorporate a higher content of $\mathrm{Al}$ than the basal plane (Z-cut).

Because the final form of grown crystal is determined by the growth rate anisotropy of principal faces such as $Z$-, $m$-, $r$ - and $z$-faces, we think that further attempts are required to better understand the complex relation between the orientation of the crystal seeds and the impurity segregation in quartz growth sectors. The authors had this problem on mind when they undertook the investigation of the morphology and the impurity distribution in growth sectors formed around the [0001] axis. For this purpose, cylindrical bars and cylindrical holes were prepared and used as seed-crystals for the hydrothermal growth of synthetic quartz. The morphology of growth sectors appearing around the [0001] direction was characterized by X-ray diffraction topography. Infrared spectroscopy and ionizing radiation were employed to reveal the distribution of point defects related to substitutional $\mathrm{Al}$ and $\mathrm{OH}$-species in $+\mathrm{X}$ - and $-\mathrm{X}$ growth sectors. It was found a different distribution of Alrelated centers in relation to the crystals grown from conventional Y-bar and Z-plate seeds.

\section{Experimental Procedure}

Z-cut plates of 3 and $18 \mathrm{~mm}$ thick were cut up on a diamond saw from a Z-bar synthetic quartz with 400 dislocations $/ \mathrm{cm}^{2}$. By using a stationary Sonic-Mill machine with a power output of $1790 \mathrm{~W}$ and frequency of $20 \mathrm{kHz}$, cylindrical holes with 12,20 and $25 \mathrm{~mm}$ in diameter were ultrasonically machined parallel to the $\mathbf{Z}$-axis. The amplitude of vibration was set at the minimum value and the static load applied on the sonotrode was kept at $25 \mathrm{~N}$. The cylindrical tools were fabricated with stainless steel. The abrasive used was silicon carbide $(\mathrm{SiC})$ with mean grain size of $25 \mu \mathrm{m}$. The slurry used was 1:2.5 (abrasive : water) by volume. The same procedure was employed to machine cylindrical bars with $18 \mathrm{~mm}$ in diameter and $18 \mathrm{~mm}$ in length. The plates enclosing the cylindrical holes and the cylindrical bars were then used as seed-crystals for the hydrothermal growth of synthetic quartz. Cylindrical geometry was selected because its permits indistinctly the growth of all sectors around a given crystal axis. The growth was carried out in a commercial autoclave at Fine Crystals Company (Japan) under $3.78 \% \mathrm{NaOH}$ solution. The pressure and the growth temperature were $145 \mathrm{MPa}$ and $363^{\circ} \mathrm{C}$, respectively. The growth period was 50 days. Figure 1 shows as-received crystals grown from a cylindrical seed-bar and a seed-plate with a cylindrical hole of $25 \mathrm{~mm}$ in diameter. The three-fold symmetry of the optic axis is clearly observed in both cases.

Three-dimensional defects in the bulk growth material were observed by optical microscopy and optical

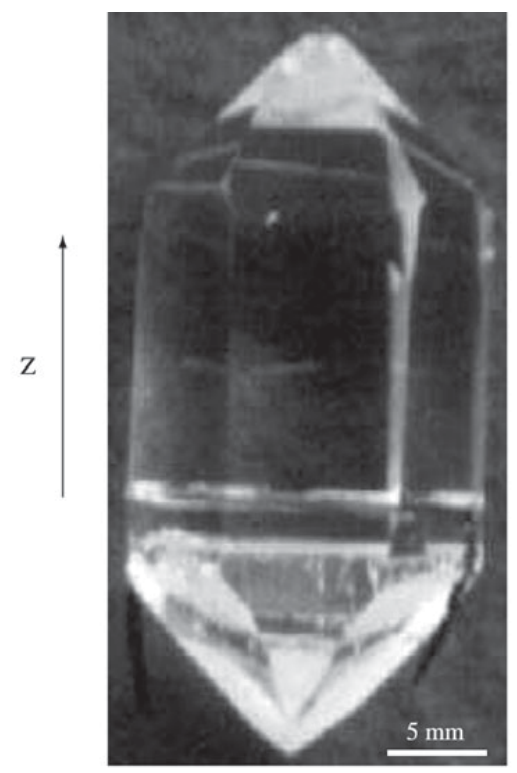

a)

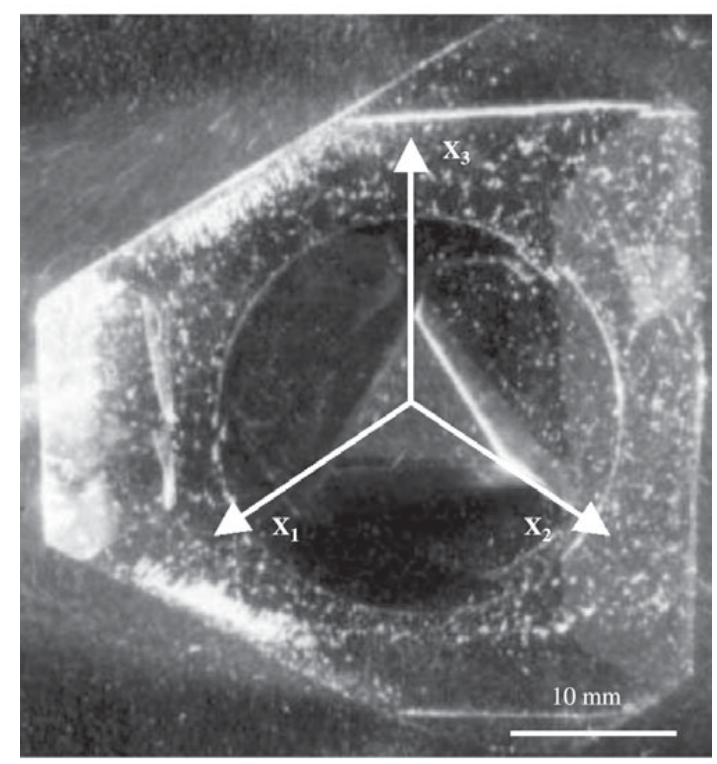

b)

Figure 1. Synthetic crystals grown from a cylindrical seed with $18 \mathrm{~mm}$ in diameter (a) and a seed-plate containing a cylindrical hole with $25 \mathrm{~mm}$ in diameter (b).

inspectoscopy ${ }^{9}$. X-ray diffraction topography (XRDT) was used to characterize the morphology of the growth sectors and the distribution of dislocations. Samples for X-ray topographic analysis were prepared following a procedure well established by Suzuki et al. ${ }^{10}$. X-ray topographs were ob- 
tained by using a non-parallel (+,-) double crystal arrangement with the transmission geometry built on the two-axis diffractometer at the XRD1 beam line of the Brazilian National Synchrotron Light Laboratory (LNLS) ${ }^{10,11}$. The first crystal was issued from a Z-bar synthetic quartz containing about 10 dislocations $/ \mathrm{cm}^{2}$. It was prepared with an asymmetric factor $(1 / \mathrm{b})$ equal to 17 with $13 \mathrm{~mm}$ wide, $20 \mathrm{~mm}$ height and $70 \mathrm{~mm}$ long ${ }^{11}$. The reflecting plane of the asymmetric crystal was (1011). The diffraction images were collected on high-resolution IX50 Fuji films. By using this setting, it was possible to get high-contrast and high-resolution topographies in relatively short periods of time (about 45 min with synchrotron radiation compared to $20 \mathrm{~h}$ with a conventional source) due to the high collimation and the high intensity of the synchrotron radiation beam.

Ionizing irradiation and infrared absorption spectroscopy (IRS) were employed to characterize the distribution of Aland $\mathrm{OH}$-related point defects incorporated into the growth sectors. Ionizing irradiation and IRS were performed on optically polished samples cut perpendicular to the $\mathbf{Z}$-axis. Ionizing irradiation was performed at room temperature with $\gamma$-rays by using a ${ }^{60} \mathrm{Co}$ source. The specimens were exposed to a dose of $10 \mathrm{kGy}$. IR spectra were obtained at room temperature with an unpolarized beam using an IFS66 Bruker FT-IR Spectrometer. Each spectrum was recorded after 250 scans with the resolution better than $4 \mathrm{~cm}^{-1}$ in the $3 \mu \mathrm{m}$ region. The molecular $\mathrm{H}_{2} \mathrm{O}$ content was evaluated by using the calibration proposed by Paterson ${ }^{12}$ and the numerical integration of the broad band ${ }^{13}$ between 3700 and $2900 \mathrm{~cm}^{-1}$. The (decadic) absorption coefficients $(\alpha)$ of the sharp bands appearing superposed upon the broad $\mathrm{OH}$ band were evaluated by the Beer-Lambert formula.

\section{Results and Discussions}

\subsection{Solid inclusions}

Figure 2a shows the seed-plate containing partially filled holes of 12 and $20 \mathrm{~mm}$ in diameter. This figure was obtained by optical inspectoscopy from the central part of the crystal, after removing the natural faces. Halos of scattered light were observed at seed-crystal interfaces. For all samples, maximum light scattering was located at the same position. Optical microscopy analysis revealed that voids and clusters of misshapen solid inclusions are responsible for the light scattering shown in Fig. 2a. The inhomogeneous distribution of voids and inclusions was explained by the position of the seed-plate in relation to the flow of the growing solution inside the autoclave. The seed plates were fixed in such a way that the holes remained perpendicular to the convection flow of the growing solution. As a result solid precipitates accumulated at the bottom of the cylindrical holes inhibiting the crystallization in the first stage of the growing process. In addition, solid inclusions with defined

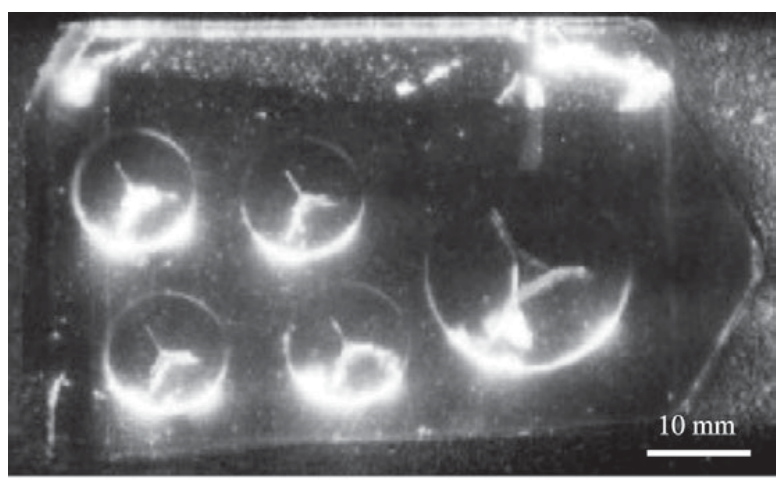

a)

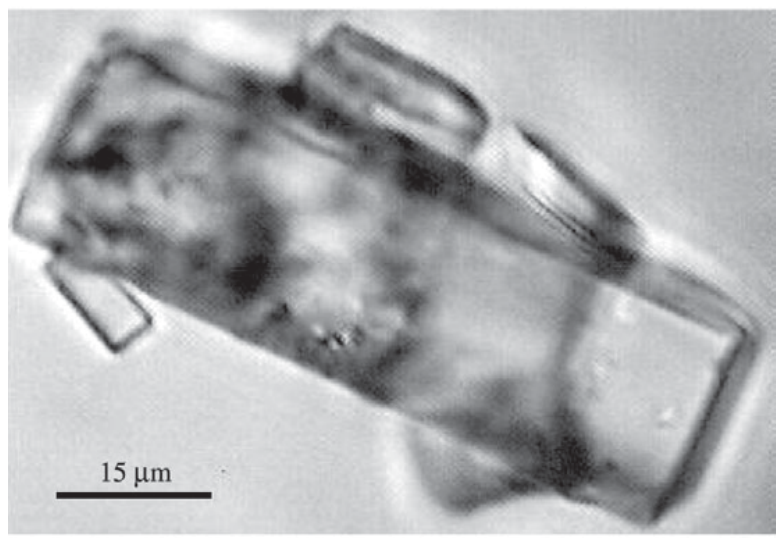

b)

Figure 2. Z-cut plate containing cylindrical holes partially filled by the hydrothermal growth (a) and solid inclusions observed at the seed-crystal interface (b).

crystal faces (Fig. 2b) were observed in overall seed-crystal interfaces. Solid inclusions observed in crystals grown from cylindrical holes are usually larger than those observed in crystals grown from cylindrical bars. In average, the length of such inclusions is ranged from 5 to $80 \mu \mathrm{m}$.

\subsection{Dislocations and growth sectors}

Prismatic habit right-handed quartz crystals with $m-, r$, $z$ - and $x$-faces grew from cylindrical seeds prepared by USM. A schematic representation of a Z-cut plate of an as-grown crystal is shown in Fig. 3 together with characteristic patterns of growth sectors imaged by XRDT. The identification of $+\mathrm{X}$ - and $-\mathrm{X}$-growth directions was determined by the etching figures ${ }^{9}$ in a plate cut parallel to the specimen used for X-ray topography. Figure 4 shows $+X$ - and $-X$ sectors grown around the cylindrical hole parallel to the $\mathrm{Z}$-axis.

In Fig. 3 and 4, it is observed that single dislocations 

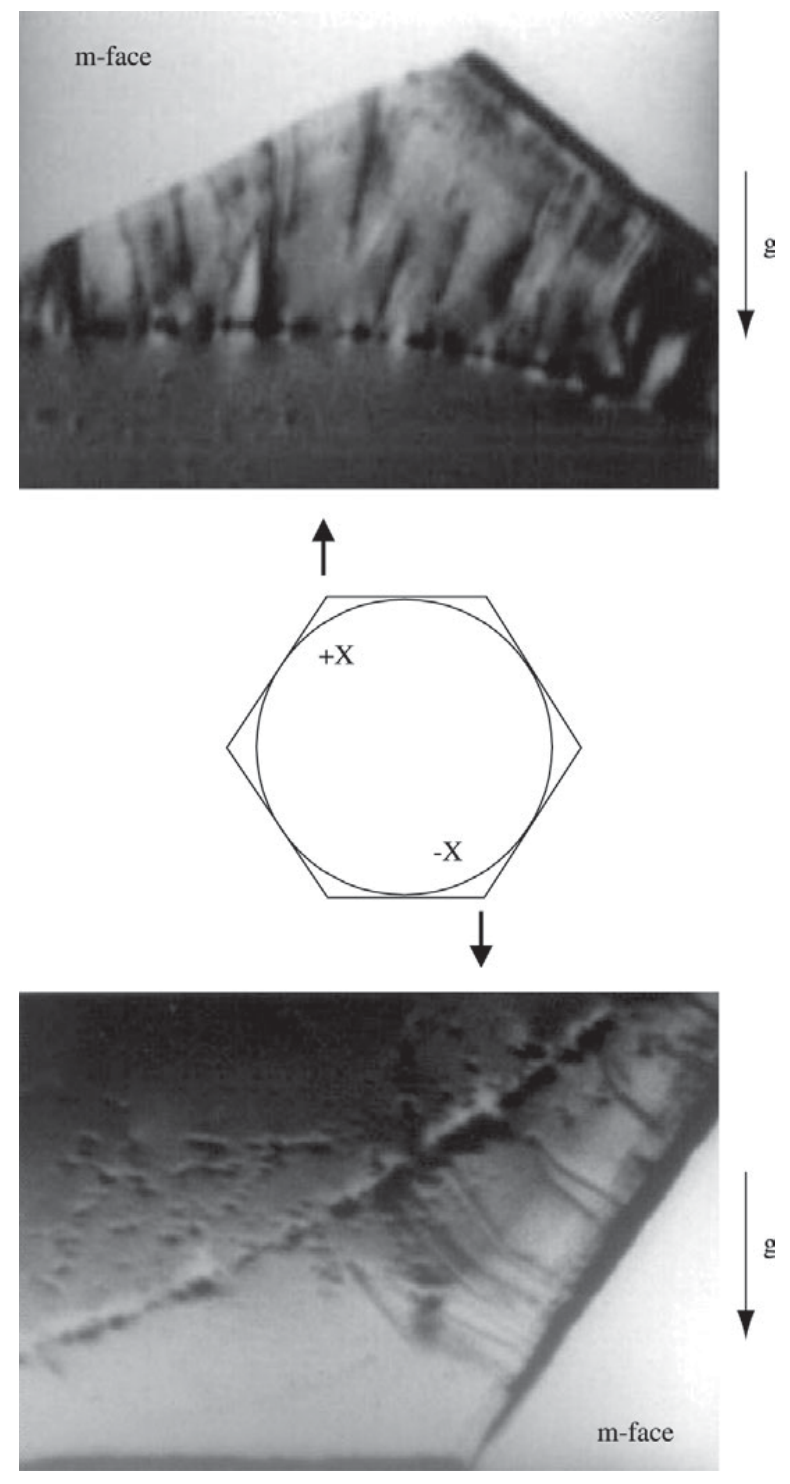

Figure 3. Schematic representation of a crystal grown from a Z-bar cylindrical seed of $18 \mathrm{~mm}$ diameter and the respective $\mathrm{X}$-ray topographic images (refection $20 \overline{2} 0$ ) of $+\mathrm{X}$ - and $-\mathrm{X}$ growth sectors.

and dislocation bundles nucleate from dark dots distributed around the seed-crystal interface. These dots represent intense localized lattice strain and are probably caused by solid inclusions. Such inclusions probably grew from foreign particles or from mechanical damage on the seed surface. In the second case, solutions droplets were probably trapped at the surface imperfections produced by USM (microcracks and scratches) and it is believed that all dislocations originate by lattice mismatches induced by such inclusions. We

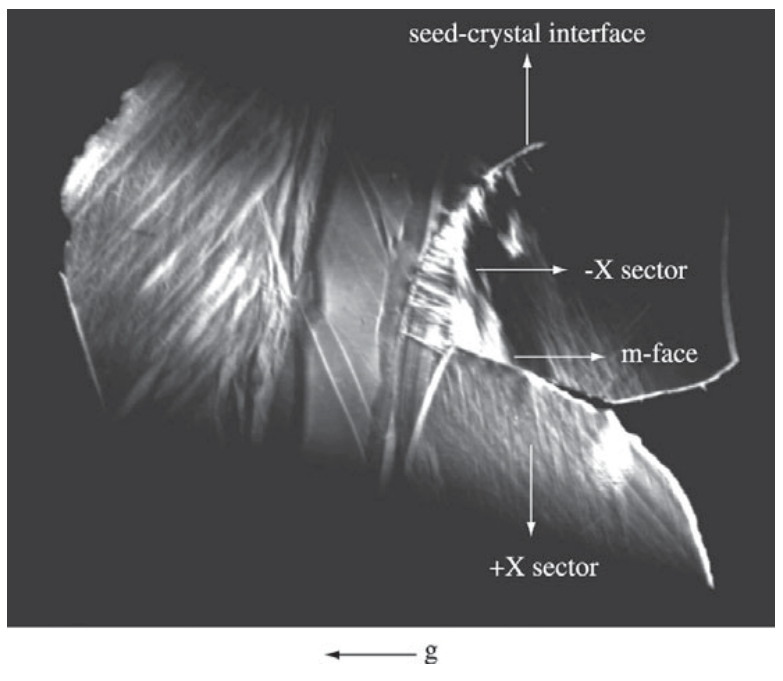

Figure 4. Z-plate seed containing cylindrical hole imaged by Xray diffraction topography (reflection $\overline{2} \overline{2} 40$ ) showing $+\mathrm{X}$ - and $-\mathrm{X}$ growth sectors.

may also infer that the thermal etching produced by the growing solution during the heating period of the hydrothermal growth was not effective to eliminate the surface damages produced by USM. In the $-X$-growth sector shown in Fig. 3, dislocations lines initially parallel to $\mathbf{X}$-axis are bent in a direction perpendicular to the $m$-face when its passes through the growth striations. These striations are probably the traces of planes parallel to $r$ - and $z$-faces appearing during the growth process ${ }^{14}$.

Figures $2 \mathrm{a}$ and 4 show that cylindrical holes were not completely filled during the hydrothermal growth. It is explained by the anisotropy of the growth velocities between the faces formed around the $\mathbf{Z}$-axis. $+X$-faces growth 2.5 times faster than $-X$-faces and the growth velocity of $m$ faces is nearly zero ${ }^{1,4} \cdot m$-faces appearing at the boundary between $+X$ - growth sectors inhibit the progress of the growing layer. It is believed that the progress of the growth layer is also affected by the decrease of the free space inside the hole. The circulation of the growing solution around the growing layers is probably restrained as the hole is fulfilled. The effect of the $m$-faces is immediately noticeable on crystals grown from cylindrical bars. The appearance of $m$-faces in the early stages of the growth process inhibits the growth of $+\mathrm{X}$ - and $-\mathrm{X}$-growth sectors.

\subsection{Segregation of $\mathrm{Al}$ - and $\mathrm{OH}$ - species}

Figure 5 shows the darkening patterns resultant from $\gamma$ ray irradiation of $Z$-cut plates. For the crystal grown from the seed containing a cylindrical hole, the distinction between $+\mathrm{X}$ - and $-\mathrm{X}$ - growth sectors is straightforward. In 


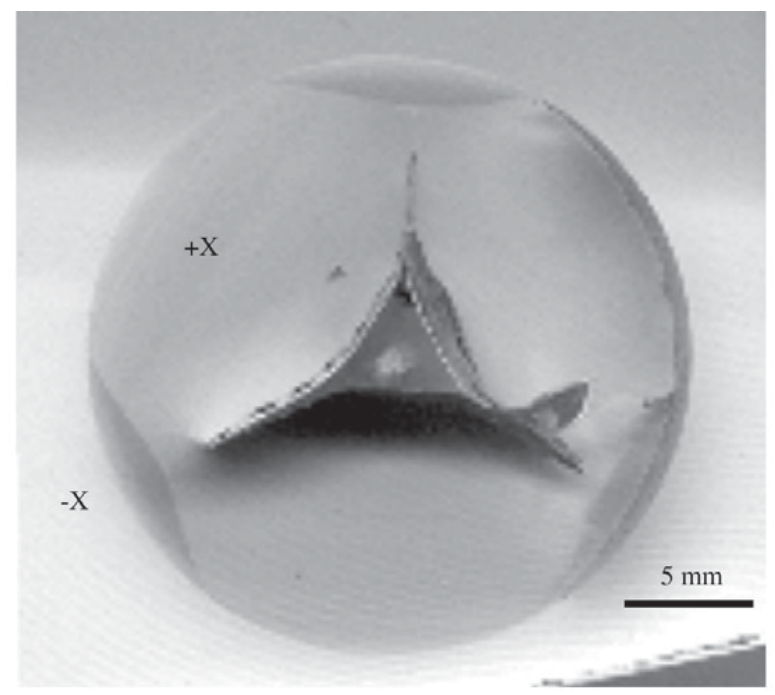

a) Cylindrical hole seed

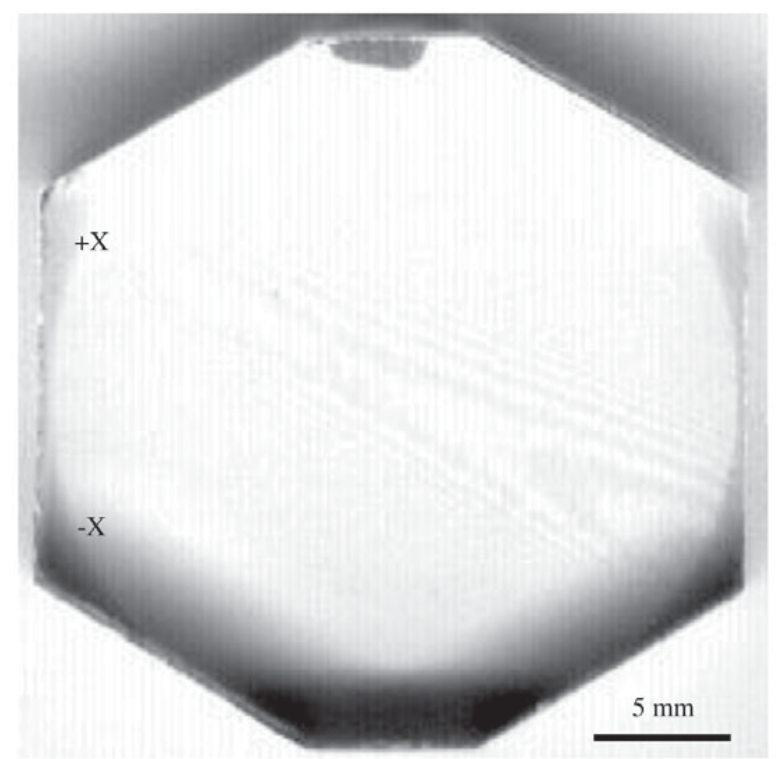

b) Cylindrical bar seed

Figure 5. $+\mathrm{X}$ - and $-\mathrm{X}$ - sectors grown from seeds parallel to [0001] and revealed by $\gamma$-irradiation.

case of the crystal grown from the cylindrical bar $+\mathrm{X}$ - and $\mathrm{X}$ - growth sectors were distinguished by etching figures. For both crystals, it is observed that $-\mathrm{X}$ - growth sectors have a higher intensity of darkening than $+\mathrm{X}$ - growth sectors. Comparing Fig. 5a and 5b, it is also observed that the intensity of darkening is considerably lower for the growth sec- tors appearing in the crystal grown from the cylindrical bar.

Typical IR absorption spectra of $+\mathrm{X}$ - and $-\mathrm{X}$ - growth sectors are shown in Fig. 6. For both crystals, the intensity of the broad $\mathrm{OH}$ band is higher for - $\mathrm{X}$ - growth sectors compared to $+\mathrm{X}$ - growth sectors. In addition, the intensities of broad and sharp absorption bands for the growth sectors originated from the cylindrical hole are higher than those found in the sectors originated from the cylindrical bar seed. Table 1 summarizes the intensities of $\mathrm{OH}$-species associated with the broad band and the sharp bands appearing at 3584 and $3379 \mathrm{~cm}^{-1}$. Sharp bands at 3584 and $3379 \mathrm{~cm}^{-1}$ are due to as-grown $\mathrm{OH}$ and $\mathrm{Al}-\mathrm{OH}$ point defects, respectively ${ }^{15,16}$.

The selective distribution of impurity-related point defects in growth sectors formed around the $\mathbf{Y}$-axis is well $\mathrm{known}^{2-6}$. Similarly, the artificial smoky color due to ionizing irradiation is not uniformly distributed throughout the $\mathbf{Y}$-axis. Bambauer ${ }^{17}$ was the first one to report the selective smoky color in different faces of natural quartz. He reported that $\mathrm{Al}$ and $\mathrm{Li}$ contents and the darkening degree (DD) increase in the sequence $m<r<z$. The intensity of smoky color increases with increasing the coupled substitution of $\mathrm{Al}$ and $\mathrm{Li}$. More recently, it was shown that the darkening grade induced by $\gamma$-irradiation has a positive correlation with the $[\mathrm{Li}] /[\mathrm{OH}]$ ratio for both synthetic and natural quartz ${ }^{5,13}$. Under ionizing irradiation at room temperature, $\mathrm{Al}-\mathrm{Li}$ is easily transformed to Al-hole than $\mathrm{Al}-\mathrm{OH}$ center. Thus, the differential smoky coloration is connected with relative variations in the content of $\mathrm{Al}, \mathrm{Li}$ and $\mathrm{OH}$-species in solid solutions in successive growth sectors of the crystal. For Y-bar synthetic crystals it was shown that DD increase in the sequence $\mathrm{Z}<-\mathrm{X}<+\mathrm{X}<\mathrm{S}$. In this study, Fig. 5 shows that DD is higher for $-\mathrm{X}$ - compared to $+\mathrm{X}$ - growth sectors. This fact suggests that the $[\mathrm{Li}] /[\mathrm{OH}]$ ratio is higher for $-\mathrm{X}$-growth sector when Z-bar seeds are used instead of $\mathrm{Y}$ bars. -Xgrowth sectors originated around the $\mathbf{Z}$-axis trap larger amounts of $\mathrm{Li}$ ions giving rise to a higher content of $\mathrm{Al}-\mathrm{Li}$ centers. After irradiation, $\mathrm{Al}-\mathrm{Li}$ centers are converted to $\mathrm{Al}$ hole and $\mathrm{Al}-\mathrm{OH}$ centers ${ }^{18}$, which are responsible for the smoky color and the sharp band appearing at $3379 \mathrm{~cm}^{-1}$, respectively. Therefore, we may conclude that [Al] and [Li] trapped by $+\mathrm{X}$ - and $-\mathrm{X}$ - growth sectors are affected by the crystallographic orientation of the seed-crystal.

From the crystallographic point of view, $+X$ - and $-X$ faces are quite different. The main structural differences between these faces are the electrical polarity and the growth velocity. For a right-hand crystal, the growth velocity for $+X$ - is about 2.5 times higher than for $-X$ - face ${ }^{1,4}$. The slowest growth rate of the $-X$-face is probably connected with the capture of $\mathrm{OH}$ species during the hydrothermal growth. According to the adsoprtion layer theory ${ }^{19}$, the existence of a film of adsorbed water on the surface of the growing crys- 
Table 1. Broad $\mathrm{OH}$ band content $[\mathrm{OH}]$ and intensities of sharp absorption bands $(\alpha)$ measured on $+\mathrm{X}$ - and $-\mathrm{X}$ - growth sectors grown from cylindrical bar and cylindrical hole seed-crystals parallel to [0001].

\begin{tabular}{cccccc}
\hline seed-crystal & condition & Growth & {$[\mathrm{OH}]$} & $\begin{array}{c}\alpha_{3584} \\
\left(\mathrm{~cm}^{-1}\right)\end{array}$ & $\begin{array}{c}\alpha_{3379} \\
\left(\mathrm{~cm}^{-1}\right)\end{array}$ \\
\hline bar, $18 \mathrm{~mm}$ & Sector & $+\mathrm{X}$ & 8 & 0.01 & - \\
& as-grown & $-\mathrm{X}$ & 30 & 0.04 & - \\
& Irradiated, $10 \mathrm{kGy}$ & $+\mathrm{X}$ & 6 & 0.005 & 0.01 \\
hole, $20 \mathrm{~mm}$ & & $-\mathrm{X}$ & 25 & - & 0.02 \\
& Irradiated, $10 \mathrm{kGy}$ & $+\mathrm{X}$ & $55(8)^{*}$ & 0.03 & 0.09 \\
\hline
\end{tabular}

*standard deviation of three measurements

- not observed
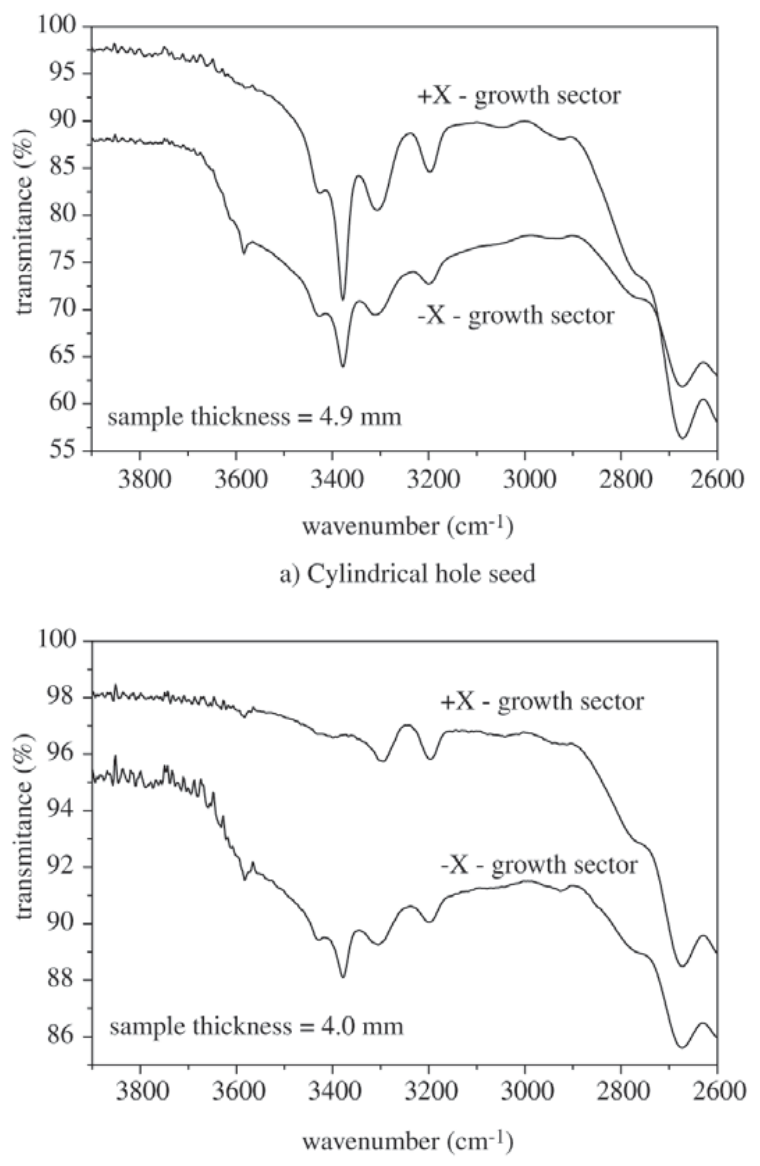

b) Cylindrical bar seed

Figure 6. IR absorption spectra of $+X$ - and $-X$ - growth sectors obtained after $\gamma$-irradiation. Spectra were displaced from its original transmittance position to better observation.

tal may inhibit the growth process. As it is shown in Table 1 for $+\mathrm{X}$ - and $-\mathrm{X}$-growth sectors appearing around the $\mathbf{Z}$ axis, previous investigations showed that the content of $\mathrm{OH}$ species in $-\mathrm{X}$-growth sector is considerably higher com- pared to the other growth sectors appearing around the $\mathbf{Y}$ axis ${ }^{4}$. Besides the $\mathrm{OH}$ species, the threefold symmetry of the $\mathbf{Z}$-axis is also contributing for the segregation of $\mathrm{Al}$ and $\mathrm{Li}$ impurities to growth layers parallel to $-X$ - faces. This difference may be preliminary explained as follows. During the growth process, foreign atoms tend to be rejected to regions with slow growth rates. The three-fold symmetry of the $\mathbf{Z}$-axis permits the occurrence of three $-\mathrm{X}$-growth sectors whereas the twofold symmetry of the $\mathbf{Y}$-axis permits the occurrence of only one $-\mathrm{X}$-growth sector. Thus, impurity species have a higher probability to be trapped by $\mathrm{a}-X$ - face in crystals grown around the $\mathbf{Z}$-axis.

Impurity segregation is still more critical in the case of the cylindrical holes because the growth solution is restrained around the growth surfaces. Consequently the mechanism of impurity trapping on $+X$ - and $-X$ - growth faces should be more intense than that existing around the cylindrical seed bars.

\section{Conclusion}

The results of the present work can be summarized as follows:

- Solid inclusions grown on seed crystal interface are responsible for the nucleation of dislocation bundles appearing in $+\mathrm{X}$ - and $-\mathrm{X}$ - growth sectors formed around the $\mathbf{Z}$-axis.

- The growth of $+\mathrm{X}$ - and $-\mathrm{X}$ - sectors are inhibited by the appearance of $m$-faces in the early stages of growth. In case of seed plates containing cylindrical holes, the growth process is also restrained due to difficulties found by the growing solution to reach the growing surfaces as the holes are fulfilled.

- The incorporation of Al-related centers on $+X$ - and $X$ - faces are affected by the crystallographic orientation of the seed crystal. Compared to $+\mathrm{X}-$ and $-\mathrm{X}$ growth sectors of standard Y-bar seeds, IR and $\gamma$-irradiation analyses show that not only $\mathrm{OH}$ but also $\mathrm{Al}$ and $\mathrm{Li}$ impurities are mainly captured by the $-\mathrm{X}$ growth sectors appearing around the $\mathbf{Z}$-axis of crystals grown from cylindrical seeds. 


\section{Acknowledgements}

The authors are grateful to Mr. Yutaka Mikawa from Fine Crystals Co. (Muroran-shi, Japan) for the crystal growing and Ms. Angela Lucena from EMBRARAD (São Paulo) for the $\gamma$-irradiation of quartz samples. This study was supported by LNLS/CNPq (XRD 680/00) and PROPESQ/UFPE. One of the authors (P.L.G.) is grateful for the financial support provided by the program PROFIX/CNPq and H.A.D.C is thankful for the scholarship provided by PIBIC/UFPE/CNPq.

\section{References}

1. Demianets, L.N.; Lobachev, A.N. Current Topics in Materials Science, Kaldys, E. eds., North-Holland Pub. Co., v. 7, p. 483-584, 1981.

2. Cohen, A.J. J. Phys. Chem. Solids, v. 13, p. 321, 1960.

3. Chakraborty, D.; Lehmann, G. J. Solid State Chem., v. 17, p. 305, 1976.

4. Iwasaki, F.; Shinohara, A.H.; Iwasaki, H.; Suzuki, C.K. Jpn J. Appl. Phys., v. 29, p. 1139, 1990.

5. Iwasaki, F.; Iwasaki, H. Jpn. J. Appl. Phys., v. 32, p. 893, 1993.

6. Kawasaki, M. J. Crystal Growth, v. 155, p. 75, 1995.

7. Brown, C.S.; Thomas, L.A. J. Phys. Chem. Solids, v. 13, p. $337,1960$.

8. Armington, A.F.; Bruce, J.A.; Halliburton, L.E.; Markes, M.E. J. Crystal Growth, v. 49, p. 739, 1980.

9. Heising, R.A. Quartz Crystals for Electrical Circuits, Van Nostrands Co. Inc., NY, USA, p. 536, 1946.

10. Suzuki, C.K.; Shinohara, A.H.; Oliveira, V.A.R.; Takya, S.; Kiss, J. Proc. of the $40^{\text {th }}$ Ann. Symp. on Freq. Control, New York, p. 47, 1986.

11. Shinohara, A.H.; Mota, C.S.; Silva, J.L.; Guzzo, P.L.; Costa, H.A.D.; Hiramatsu,C.Q.; Suzuki, C.K.; Kycia, S.; Franco M. Annual Report of $L N L S$, v. 3, p. 9, 2000.

12. Paterson, M.S. Bull. Minéral., v. 105, p. 20, 1982.

13. Guzzo, P.L.; Iwasaki, F.; Iwasaki, H. Phys. Chem. Minerals, v. 24, p. 254, 1997.

14. Lang, A.R. Adv. on X-ray Analysis, v. 10, p. 91, 1967.

15. Lipson, H.G.; Kahan, A. J. Appl. Phys., v. 58, p. 963 , 1985.

16. Kats, A. Philips Res. Repts., v.17, p. 113, 1962.

17. Bambauer, H.U. Schweiz. Mineral. Petrogr. Mitt., v. 41, p. $335,1961$.

18. Halliburton, L.E.; Koumvakalis, N.; Markes, M.E.; Martin, J.J. J. Appl. Phys., v. 52, p. 3565, 1981.

19. Chernov, A.A.; Kuznetsov, V.A. Sov. Phys. Crystallogr., v.14, p. $753,1970$. 
